\title{
SLIP DISTRIBUTION OF THE 19 SEPTEMBER 1985 MICHOACAN, MEXICO, EARTHQUAKE: NEAR-SOURCE AND TELESEISMIC CONSTRAINTS
}

\author{
By Carlos Mendoza and Stephen H. Hartzell
}

\begin{abstract}
We simultaneously invert the strong-motion velocity records and the long- and intermediate-period teleseismic $P$ waveforms of the 19 September 1985 Michoacan, Mexico, earthquake to recover the distribution of slip on the fault using a point-by-point constrained and stabilized, least-squares inversion method. A fault plane with strike fixed at $300^{\circ}$ and dip fixed at $14^{\circ}$ is placed in the region of the earthquake hypocenter and divided into 120 subfaults. Rupture is assumed to propagate at a velocity of $2.6 \mathrm{~km} / \mathrm{sec}$ away from the hypocenter. Synthetic nearsource ground motions and teleseismic $P$ waveforms for pure strike-slip and dipslip dislocations are calculated for each subfault. The observed data are then inverted to obtain the amount of strike-slip and dip-slip displacement required of each subfault. We also invert the data sets using a time-window procedure where the subfaults are allowed to slip up to three times. This approach relaxes the constraint of fixed subfault rupture time imposed by a constant rupture velocity.

Inversion of the strong-motion data alone yields a slip model similar to the solution previously obtained using only teleseismic waveforms. This result supports the use of teleseismic waveform data for the derivation of fault dislocation models in the absence of strong-motion recordings. Our simultaneous inversion of both data sets suggests that rupture during the Michoacan earthquake was controlled largely by the failure of three major asperities located along the length and down the dip of a $150-\mathrm{km}$ segment of the Cocos-North America plate boundary. The solution contains three major source regions including an $\mathbf{8 0 ~} \mathbf{~ k m}$ by $55 \mathrm{~km}$ source near the hypocenter with a peak slip of 6.5 meters. Two additional sources are present on the southeast portion of the fault about $70 \mathrm{~km}$ away from the hypocenter. One of these sources, with a peak slip of 5 meters, covers a 45 $\mathrm{km}$ by $60 \mathrm{~km}$ area and extends downdip from a depth of about $10 \mathrm{~km}$ to $24 \mathrm{~km}$. The third source region is somewhat smaller $(30 \mathrm{~km}$ by $60 \mathrm{~km}$ area, 3.1-meters peak slip) and extends further downdip at depths between $27 \mathrm{~km}$ and $39 \mathrm{~km}$. Aftershock activity following the earthquake was associated mainly with the two shallow sources. These two sources are separated by the aftershock zone of the 1981 Playa Azul earthquake.
\end{abstract}

\section{INTRODUCTION}

In a previous three-dimensional study of the teleseismic $P$ waveforms recorded for the 19 September 1985 Michoacan, Mexico, earthquake, we found that coseismic rupture involved the failure of several large source regions on the earthquake fault (Mendoza and Hartzell, 1988). The distribution of fault slip derived from the teleseismic data suggests that these source regions represent asperity zones on the interplate boundary between the subducting Cocos plate and the overriding North American plate. Houston (1987) obtained a similar pattern of moment release on the fault by applying the method of Kikuchi and Fukao (1985) to the teleseismic data. The Kikuchi and Fukao (1985) method is a nonlinear scheme that involves the iterative deconvolution of point-source responses from the observed displacement waveforms. Point sources resolved by Houston (1987) are located in the same general positions on the fault as the areas of maximum slip that we obtain by assuming a constant propagation of rupture. 
The 1985 Michoacan earthquake was also recorded by the Guerrero accelerograph array installed by the University of California, San Diego, and the Universidad Nacional Autónoma, Mexico City, along the Michoacan and Guerrero coasts (Anderson et al., 1986). A separate analysis of these strong-motion data would help assess the validity of the previous teleseismic results. In this paper, we invert velocity records obtained from the acceleration data recorded at the four Guerrero array stations nearest the epicenter to obtain an independent model of slip for the Michoacan earthquake. We then compare the resulting model with the distribution of slip obtained by Mendoza and Hartzell (1988) using only the teleseismic data. In addition, we conduct a joint inversion of both the near-source and teleseismic observations to provide a maximum constraint on the pattern of main shock slip.

\section{METHOD}

We apply the point-by-point inversion scheme used previously in our teleseismic analysis of the Michoacan earthquake (Mendoza and Hartzell, 1988). This inversion method has also been used successfully by Hartzell and Heaton $(1983 ; 1986)$ to invert strong-motion data for the rupture history of the 1979 Imperial Valley and 1984 Morgan Hill earthquakes. In the method, a fault plane of fixed dimensions and orientation is first embedded at the appropriate depth in the crustal structure of the earthquake source region. The fault is then subdivided into $\mathrm{N}$ subfaults of equal size, and point sources are uniformly distributed over each subfault. Pointsource spacing is chosen so that failure of the subfault appears smooth for a rupture propagating at a constant velocity away from the hypocenter. Assuming uniform displacements for both strike-slip and dip-slip components, synthetic waveforms are subsequently generated for each subfault at all the stations to be used in the inversion.

The synthetic waveforms and observed data comprise an overdetermined system of linear equations of the form $\mathbf{A x}=\mathbf{b}$, where $\mathbf{A}$ is an $\mathrm{m}-\mathrm{by}-\mathrm{n}$ matrix of the synthetics, and $\mathbf{b}$ is an $\mathbf{m}$-length vector containing the seismic observations. The vector $\mathbf{x}$, of length $n$, contains the subfault dislocation weights required of each component to reproduce the observed data. These weights are computed with the Householder least-squares inversion scheme of Lawson and Hanson (1974), which places a positivity constraint on the solution. This constraint is physically desirable and also minimizes instabilities that may result from destructive interference between subfaults. Additional stability is achieved by requiring a smooth variation of slip across the fault or by finding the solution with the minimum moment. These requirements are met by appending a set of linear constaints of the form $\lambda \mathbf{F x}=\lambda \mathbf{d}$, where $\lambda$ is a scalar weighting factor. If $\mathbf{F}$ and $\mathbf{d}$ are chosen so that the difference between adjacent dislocation weights is zero, then the solution will vary smoothly from subfault to subfault. Moment minimization is achieved by reducing the length of the vector $\mathbf{x}$. This occurs when $\mathbf{F}$ is the identity matrix and $\mathbf{d}$ is the zero vector. A more complete description of the inversion procedure is given by Hartzell and Heaton (1983).

\section{InVERsion of Strong-Motion Data}

We used the strong-motion data recorded by the four closest stations of the Guerrero accelerograph network (Anderson et al., 1986). These four sites include the three stations located above the observed aftershock zone and the station closest to the southern edge of the aftershock area. Figure 1 shows the location of the four instrument sites. Except for the CAL station (Caleta de Campos), the instrument trigger times are known. However, because all the stations may not have triggered 


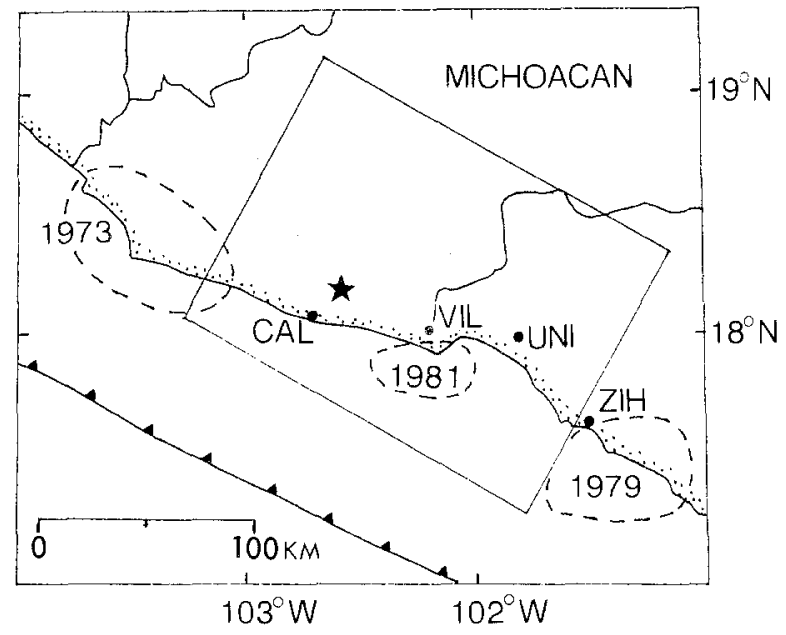

FIG. 1. Geographic map of the Michoacan, Mexico, coast showing the surface projection of the fault dimensions used in the analysis of the 19 September 1985 Michoacan earthquake. The fault is buried at a depth of $6 \mathrm{~km}$ and dips to the northeast at an angle of $14^{\circ}$. The earthquake epicenter is indicated by the star symbol. Also shown are the 4 strong-motion sites of the Guerrero array used in the study and the aftershock areas (dashed) of the 1973 Colima, the 1981 Playa Azul, and the 1979 Petatlan earthquakes (Anderson et al., 1986).

on the same seismic phase, time shifting relative to the trigger times may be necessary in the inversion to obtain the best-fitting slip model. Time shifts are also required to account for hypocenter error and to accommodate departures of the chosen velocity model from the actual crustal structure.

The CAL instrument triggered twice within a 60 -sec period. Anderson et al. (1986) attributed this double trigger to the presence of two subevents at the earthquake source. We joined the two records together, taking into account the time separation between the two triggers. A maximum record length of $80 \mathrm{sec}$ is used for CAL. For VIL (La Villita) and UNI (La Unión), we use a length of $50 \mathrm{sec}$. A record length of $40 \mathrm{sec}$ is used for ZIH (Zihuatanejo). These record lengths include all the significant ground motion recorded at the respective stations.

We inverted the vertical and horizontal velocity records at all four sites. These records were obtained by Anderson et al. (1986) from a direct integration of the observed acceleration data and include a baseline correction that preserves static displacements. The velocity records contain mostly $S$-wave energy at periods longer than about 2 sec (Anderson et al., 1986). Before inversion, we lowpass-filtered the velocity records at $0.5 \mathrm{~Hz}$ using a Butterworth filter, and the data were then resampled using a time step of 0.25 sec. This serves to remove any high-frequency contributions that are not related to the source without significantly affecting the overall amplitude of the records. Also, source-related perturbations that are present in the records at frequencies much higher than $0.5 \mathrm{~Hz}$ may remain unmodeled due to our broad partitioning of the fault dimensions. Attempting to reproduce these high frequencies might introduce errors in the results. Despite the fact that we do not examine periods shorter than $2 \mathrm{sec}$, the near-source data provide valuable constraints on the distribution of slip because the data are strongly sensitive to the amplitudes and travel times of seismic phases for individual subfaults.

Green's functions used to obtain the subfault synthetics were computed with the discrete wavenumber finite-element method described by Olson et al. (1984). This procedure, which incorporates all theoretical arrivals for a linear velocity gradient, was used to produce synthetics valid at frequencies between 0.0 and $0.75 \mathrm{~Hz}$. We 
used a velocity model derived from the gradient structure obtained by Stolte et al. (1986) for the Michoacan coast (Fig. 2). $S$-wave velocities were inferred from the $P$-wave velocities assuming Poisson materials. The velocity model that we use in the teleseismic portion of our analysis is a layered structure that approximates the gradient velocity model of Stolte et al. (1986). This layered structure is the same crustal model used by Mendoza and Hartzell (1988) and yields teleseismic pointsource responses that are not significantly different from those derived with the velocity gradient.

The fault plane used in the inversion is shown projected to the earth's surface in Figure 1. This is the same fault plane considered in our earlier study of the teleseismic data (Mendoza and Hartzell, 1988). The fault dimensions, which were chosen to be generously large based on the size of the aftershock distribution, cover a length of $180 \mathrm{~km}$ and a width of $139 \mathrm{~km}$. The strike of the fault $\left(300^{\circ}\right)$ is based on the point-source mechanisms computed by other workers from an analysis of long-period teleseismic data (Eissler et al., 1986; Ekstrom and Dziewonski, 1986; Priestley and Masters, 1986; Riedesel et al., 1986). The dip is $14^{\circ}$ to the northeast, as suggested by the orientation of the aftershock zone (Stolte et al., 1986). The fault spans a depth range of 6 to $40 \mathrm{~km}$ with the hypocenter fixed at a depth of $17 \mathrm{~km}$. The epicenter is at $18.18^{\circ} \mathrm{N}, 102.57^{\circ} \mathrm{W}$, the location initially computed by the National Earthquake Information Center.

We divided the fault into 120 subfaults with dimensions of $15 \mathrm{~km}$ by $13.9 \mathrm{~km}$. This is half the number of subfaults that were used in the Mendoza and Hartzell (1988) study. The number of subfaults was reduced to decrease the computation time during the large simultaneous inversions of both teleseismic and strong-motion data. Point sources were distributed at $1-\mathrm{km}$ and $0.927-\mathrm{km}$ intervals along the strike and down the dip, respectively, of each subfault. We assumed a 2 -sec triangular source-time function for each point source. Our analysis of the teleseismic waveforms (Mendoza and Hartzell, 1988) indicated that durations much longer than 2 sec result in poorer fits to the data.

Subfault synthetics were computed for right-lateral strike-slip and pure dip-slip displacements on the fault by assuming a constant propagation of rupture away from the hypocenter. The rupture velocity was taken to be $2.6 \mathrm{~km} / \mathrm{sec}$ (approximately 70 per cent of the local shear-wave speed). In our teleseismic study (Mendoza and Hartzell, 1988), we found that rupture velocities higher than $2.6 \mathrm{~km} / \mathrm{sec}$ failed to accommodate all the slip within our intentionally large fault dimensions. Also,

VELOCITY (KM/SEC)

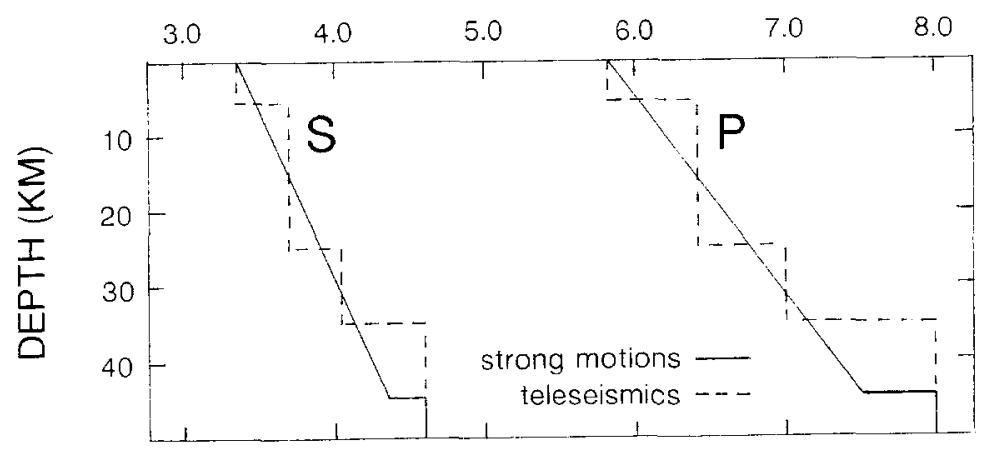

FIG. 2. Near-source velocity structure used to compute the strong-motion synthetics and the teleseismic body-wave synthetics. 
this velocity is similar to the value $(2.7 \mathrm{~km} / \mathrm{sec})$ estimated by Ekström and Dziewonski (1986) for a point source propagating unilaterally to the southeast. The subfault synthetics were lowpass filtered at $0.5 \mathrm{~Hz}$ using the same Butterworth filter applied to the observed data and then sampled at 0.25 -sec intervals.

We applied smoothing constraints in the strong-motion inversion. Our approach was to conduct several preliminary runs where we made the smoothing factor as large as possible without degrading the overall fit to the observed records. This results in the simplest possible solution. In these initial runs, we also shifted the observed records relative to the given trigger times to identify the timing appropriate for our velocity model. We found that relatively large shifts in the timing of the strong-motion records resulted in a relatively small change in the overall fit. Although the corresponding slip distributions were similar to the one we determined using only the teleseismic $P$ waveforms (Mendoza and Hartzell, 1988), the positions of the individual sources were slightly different, including a more downdip location for the source near the hypocenter. When we used the strong-motion timing indicated by the simultaneous inversion discussed in the next section, however, we obtained a significantly better fit to the data. Thus, in this case, the teleseismic data helped identify the proper strong-motion timing.

In Figure 3, we compare our final strong-motion result to the teleseismic model obtained by Mendoza and Hartzell (1988). The two distributions of slip are remarkably similar, supporting a rupture process for the Michoacan earthquake that is characterized by the failure of at least three source areas on the earthquake fault. The principal difference between the two distributions is the slip pattern on the lower portion of the fault plane. The strong-motion data appear to require a broader region with a lower value of peak slip, whereas the teleseismic data require two small areas with larger peak slips. The strong-motion solution also differs from the teleseismic result in the position of the source near the hypocenter. This source is slightly downdip compared to the position indicated by the teleseismic data. This difference may be due to a lack of resolution in the downdip direction or to unresolvable errors in the timing of the strong-motion records.

The fits between the synthetic velocity records and the observed data are shown in Figure 4. In general, the synthetics match the observed data very well at all four sites. Amplitudes following the second CAL trigger (indicated by arrows in Fig. 4) are within the noise level of the recorded data and are not deterministic in resolving features of the source. Note also that the first motion at CAL is not explained by the model. In fact, none of the solutions we obtained were able to resolve the proper first motion at this site. This could be due either to a small error in the position of the hypocenter relative to the station or to some unknown path effect. Considering the position of the CAL instrument almost directly above the earthquake hypocenter (Fig. 1), a small change in the hypocentral location could result in a polarity reversal at CAL.

An estimate of the total seismic moment can be derived by summing the products of the subfault rigidities, the subfault areas, and the corresponding slip components (Mendoza and Hartzell, 1988). For the strong-motion model we obtain a moment of $2.0 \times 10^{28}$ dyne-cm, which is greater than the moment of $1.4 \times 10^{28}$ dyne-cm computed in our earlier analysis of the teleseismic waveforms (Mendoza and Hartzell, 1988).

\section{Simultaneous Inversion of Strong-Motion and Teleseismic Data}

To better constrain the distribution of co-seismic slip for the 19 September 1985 Michoacan earthquake, we performed a simultaneous inversion using the strong- 
STRONG MOTION RESULTS

(This Study)

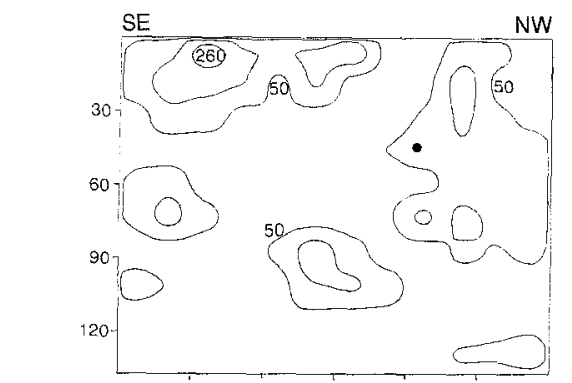

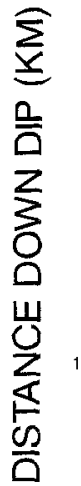



TELESEISMIC RESULTS

(Mendoza and Hartzell, 1988)



DIP

SLIP

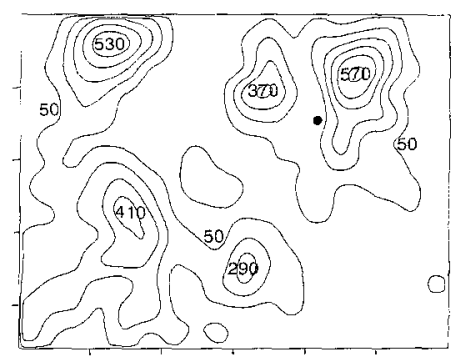

SUM



DISTANCE ALONG STRIKE (KM)

FIG. 3. Inversion results for the Michoacan earthquake obtained using strong-motion velocity records of the Guerrero accelerograph array (left side) and teleseismic $P$ waveforms (right side, Mendoza and Hartzell, 1988). Right-lateral strike-slip motion (top), pure dip-slip displacement (center), and their vector sum (bottom) are contoured on the fault presented in Figure 1 at $100-\mathrm{cm}$ intervals beginning at the $50-\mathrm{cm}$ level. The view is from above in a direction perpendicular to the fault plane. Distances downdip and along strike are relative to the upper and southeast edges of the fault. The earthquake hypocenter is indicated by the black dot.

motion and the teleseismic data sets together. Due to the relatively small amplitude of the second trigger at CAL, we considered only the initial $50 \mathrm{sec}$ recorded at that site. This increased the speed of the inversion procedure without affecting our results. As shown in the strong-motion inversion (Fig. 4), resolvable features of the Michoacan source are contained within the first CAL trigger. The teleseismic data set consists of vertical $P$ waveforms recorded by the Global Digital Seismograph Network (GDSN) and contains three long-period records of 80 -sec lengths and ten intermediate-period records of 60-sec lengths (Mendoza and Hartzell, 1988). The record lengths were chosen so that slip contributions along the entire length and width of the fault are allowed, if required by the data, without including laterarriving phases that are not incorporated into our model. These lengths generally include the entire $P$ wavetrain observed at each of the GDSN stations. 


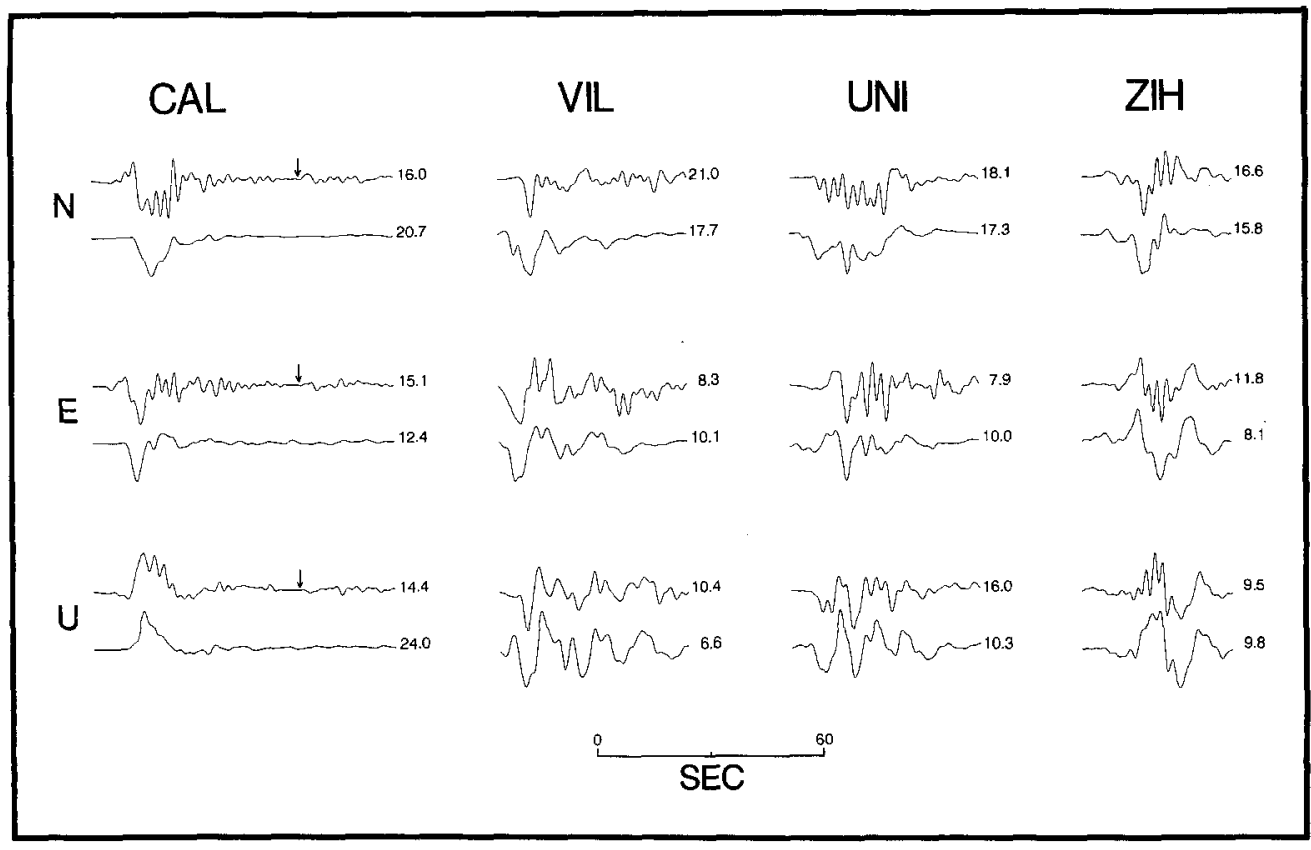

FIG. 4. Comparison of observed (upper trace) and synthetic (lower trace) strong-motion velocity records for the strong-motion dislocation model presented in the left side of Figure 3 . Peak amplitudes are in $\mathrm{cm} / \mathrm{sec}$. Synthetic amplitudes correspond to a seismic moment of $2.05 \times 10^{28}$ dyne-cm. The arrow on the CAL records marks the start time of the second trigger recorded at that site.

With the exception of AFI, none of the available teleseismic stations covered the SE quadrant of the focal sphere. The $P$-wave arrival time at AFI, however, could not be unequivocally determined due to the very emergent nature of the recorded waveform. Thus, we have not used the AFI data in our analysis. Our difficulty in identifying the direct $P$ arrival at AFI is explained by the fact that the station is at or near a node of the earthquake radiation pattern predicted by our final dislocation model.

As in the strong-motion analysis, we applied smoothing constraints in the inversion. During the preliminary runs, we found that up to 1 -sec shifts to the trigger times of the VIL, UNI, and ZIH records were necessary to match the observed data. For CAL, a 6.5-sec shift from the trigger time suggested by Anderson et al. (1986) was required. Such a time shift at CAL is not unreasonable given the fact that a trigger time was not recorded for this station. Timing of the teleseismic waveforms was not changed from that used in the Mendoza and Hartzell (1988) study. However, the teleseismic waveforms were down-weighted by 0.5 relative to the strong-motion records to give each data set an equal weight in the inversion.

The results of the simultaneous inversion are shown on the left side of Figure 5. Also shown in Figure 5 are the results of a separate inversion conducted using a left-lateral, rather than right-lateral, component of strike-slip motion. Previous centroidal analyses of the long-period teleseismic data recorded for the $1985 \mathrm{Mi}$ choacan earthquake yield mechanisms with either right-lateral or left-lateral components of strike-slip motion (Eissler et al., 1986; Ekström and Dziewonski, 1986). The seismic moments computed for each of the two solutions shown in Figure 5 are almost identical (about $1.7 \times 10^{28}$ dyne-cm). The distributions of dipslip displacement are also very similar and dominate over the strike-slip component. Because the synthetic records for the left-lateral component do not fit the observed 

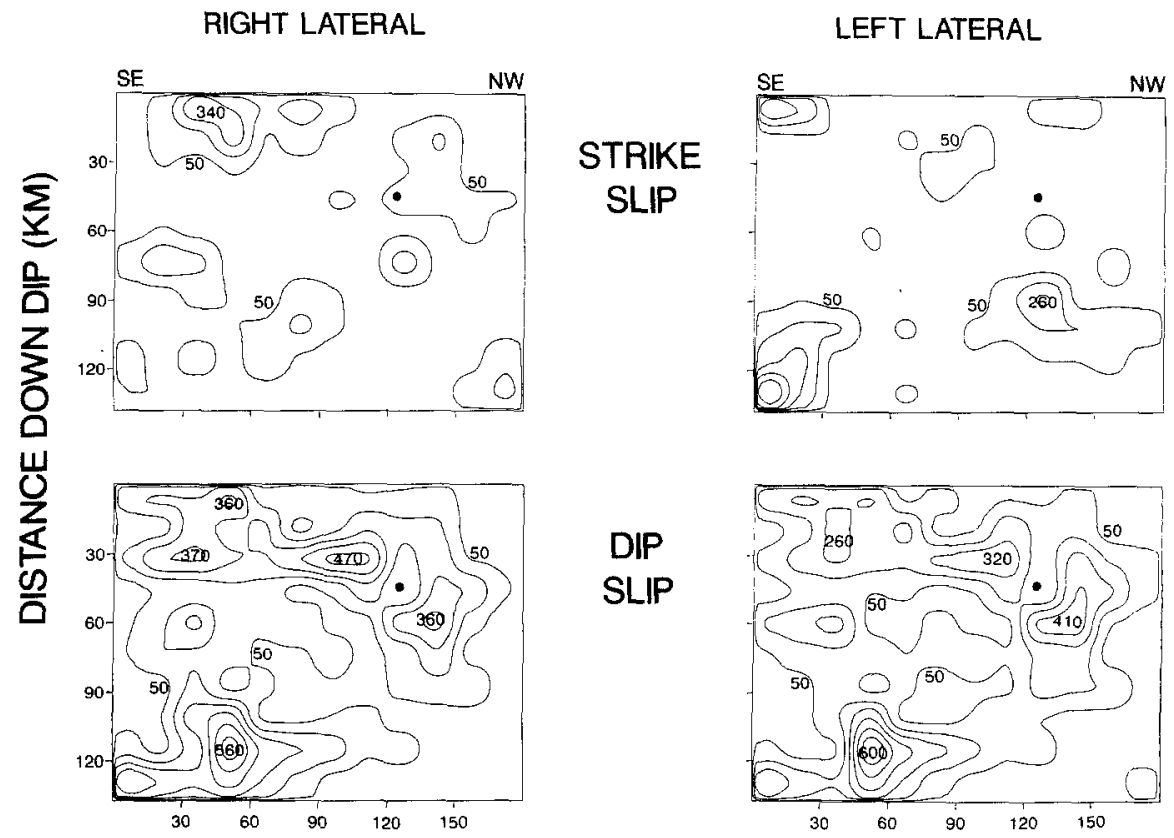

DISTANCE ALONG STRIKE (KM)

FIG. 5. Strike-slip (top) and dip-slip (bottom) displacement obtained for the Michoacan earthquake following the simultaneous inversion of the strong-motion velocity records and the teleseismic $P$ waveforms. Frames on the left side of the figure are the slip components obtained when a right-lateral component of strike-slip displacement is assumed. The frames on the right represent the solution obtained for a left-lateral component of strike-slip motion. Slip is contoured at $100-\mathrm{cm}$ intervals beginning at the $50-\mathrm{cm}$ level. The black dot represents the earthquake hypocenter.

data as well, we prefer the solution obtained with the right-lateral component of slip. Both solutions, however, fail to explain the first motion observed at CAL, suggesting that the CAL polarity is not the result of an inappropriate component of strike-slip motion. Also, the relatively small size of the strike-slip displacement indicates that strike-slip motion is not important to the overall character of the Michoacan earthquake source.

We now compare the simultaneous result to the strong-motion solution of Figure 3 . The distributions of slip are very similar except for the amount of slip obtained for the deeper downdip source on the southeast portion of the fault. This source has a peak slip that is about 2.5-meters larger in the simultaneous inversion. This result suggests that the teleseismic data are more sensitive to downdip rupture along this portion of the fault than are the near-source records. To test this hypothesis, we examined the synthetic records that would be produced at all the recording sites by each subfault if a moment of $1.5 \times 10^{28}$ dyne-cm were distributed along the entire fault dimensions. We found that, whereas the teleseismic synthetics maintain a relatively uniform maximum amplitude for all the subfaults, the maximum amplitudes of the strong-motion synthetics depend greatly on the subfault position on the fault. For example, Figure 6 shows the CAL (EW) strong-motion synthetics and the RSNT teleseismic synthetics produced by uniform dip-slip motion across several subfaults distributed down the fault. The CAL synthetics for the downdip subfaults have relatively low amplitudes that would contribute little to the overall amplitude of the synthetic record. The CAL site is thus relatively insensitive to dip-slip motion across these downdip subfaults. 
The variation in synthetic amplitudes illustrated in Figure 6 suggests that the sensitivity of each of the strong-motion sites can be measured by noting the maximum amplitude in the subfault synthetics. Figure 7 shows contour plots of the maximum amplitudes obtained for the horizontal E-W synthetics at the four recording sites for uniform dip-slip motion. The plots indicate that each strongmotion site is most sensitive to a localized region along the fault. The position of

\section{CAL E}


E


$\mathrm{H}$

\section{RSNT}

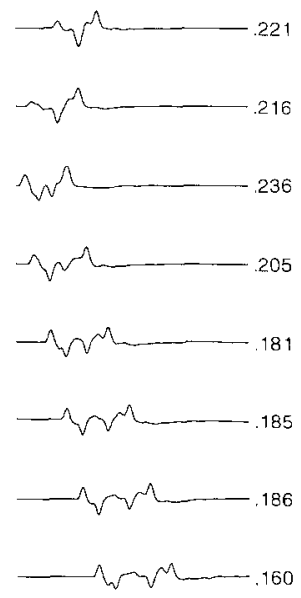

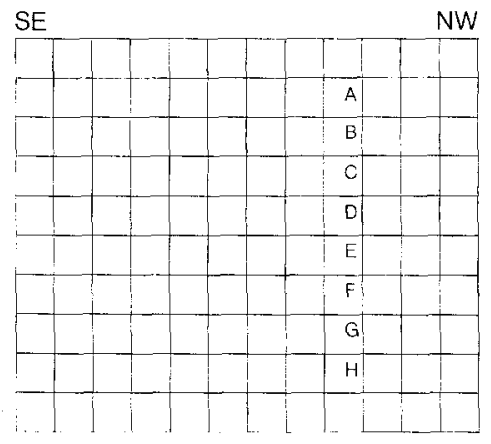

SELECTED SUBFAULT SYNTHETICS UNIFORM DIP SLIP MOTION

FIG. 6. Horizontal (E-W) strong-motion synthetics computed at the CAL site and vertical $P$-wave synthetics computed at the RSNT station for uniform dip-slip motion across the eight subfaults shown on the fault plane on the right. Amplitudes, which are measured in $\mathrm{cm} / \mathrm{sec}$ for CAL and in digital counts for RSNT, correspond to a seismic moment of $1.5 \times 10^{28}$ dyne-cm distributed over the entire fault plane.
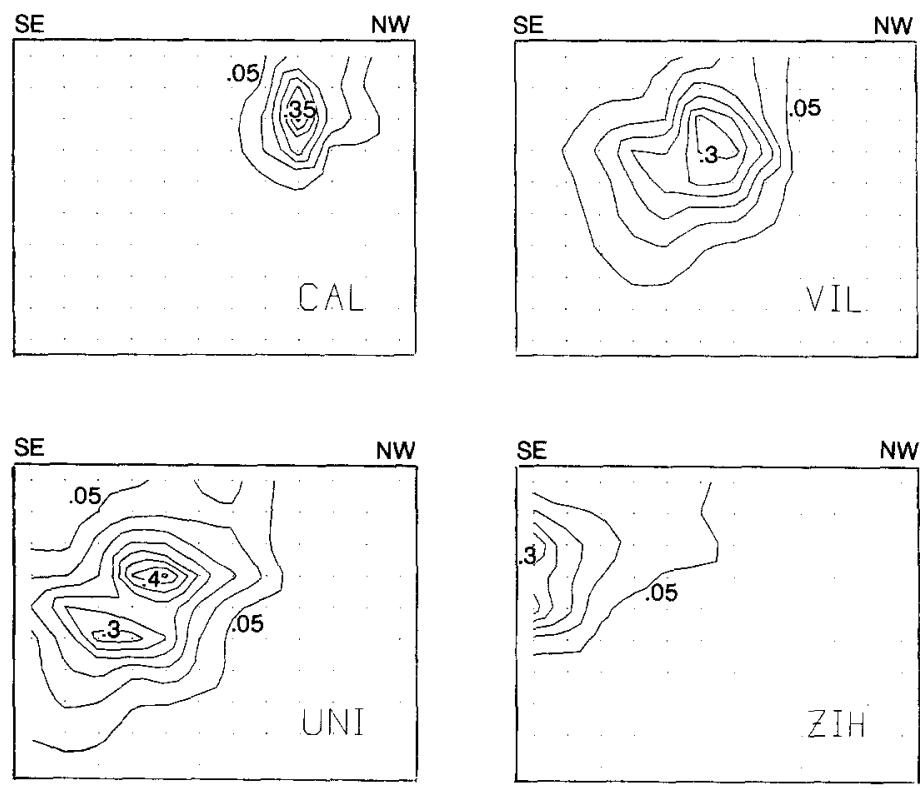

FIG. 7. Contour plots of maximum synthetic horizontal E-W amplitudes obtained at CAL, VIL, UNI, and ZIH for uniform dip-slip motion across each of the 120 subfaults shown in Figure 6 . Maximum amplitudes are contoured at $0.05 \mathrm{~cm} / \mathrm{sec}$ intervals and correspond to a seismic moment of $1.5 \times 10^{28}$ dyne-cm distributed over the entire fault plane. 
this localized region varies laterally for each station and component but generally does not include the lower third of the chosen fault plane.

The general agreement of our slip history with the results of Houston (1987) suggests that our choice of rupture velocity is approximately correct. However, a more appropriate model of the slip distribution may be obtained with our method by allowing some flexibility in the rupture time of the individual subfaults. We have incorporated such a variability in our simultaneous inversion by allowing each subfault to slip up to three times, if required by the strong-motion and teleseismic data. Each successive slip interval is delayed from the previous one by the width of the source-time function, which is $2 \mathrm{sec}$ in this case. The contribution of slip within each of the three time windows is subsequently solved for. This approach was used by Hartzell and Heaton $(1983 ; 1986)$ in the study of the 1979 Imperial Valley and the 1984 Morgan Hill earthquakes. In our application to the 1985 Michoacan earthquake, we include moment minimization, in addition to the smoothing constraint, to prevent a solution with unnecessarily large slip contributions.

The results of the time-window analysis are shown in Figure 8. We define the three time intervals, $T_{1}, T_{2}$, and $T_{3} . T_{1}$ is the first $2 \mathrm{sec}$ following the passage of the rupture front traveling at $2.6 \mathrm{~km} / \mathrm{sec} . \mathrm{T}_{2}$ is the first $4 \mathrm{sec}$ following the passage of the rupture front, and $T_{3}$ is the first $6 \mathrm{sec}$ following the passage of the rupture front.


$\mathrm{T}_{2}$
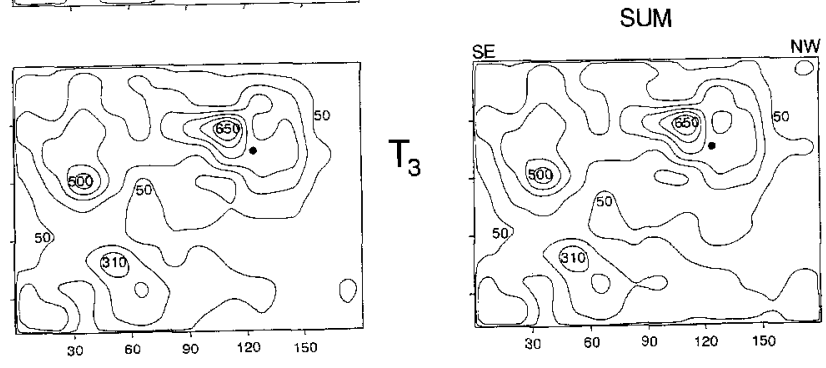

DISTANCE ALONG STRIKE (KM)

FIG. 8. Stike-slip (left side) and dip-slip (middle) displacement for the Michoacan earthquake obtained for three different time windows. Slip on the fault is shown for times of $2 \sec ($ top), 4 sec (center), and 6 $\mathrm{sec}($ bottom) following the passage of a rupture front traveling at a velocity of $2.6 \mathrm{~km} / \mathrm{sec}$. The frame in the lower right corner is the vector sum of the strike-slip and dip-slip components for time interval $\mathrm{T}_{3}$. the lower right corner is the vector sum of the strike-slip and the $50-\mathrm{cm}$ level. A seismic moment of $1.5 \times$ $10^{28}$ dyne-cm is implied by this model. The black dot represents the earthquake hypocenter. 


(

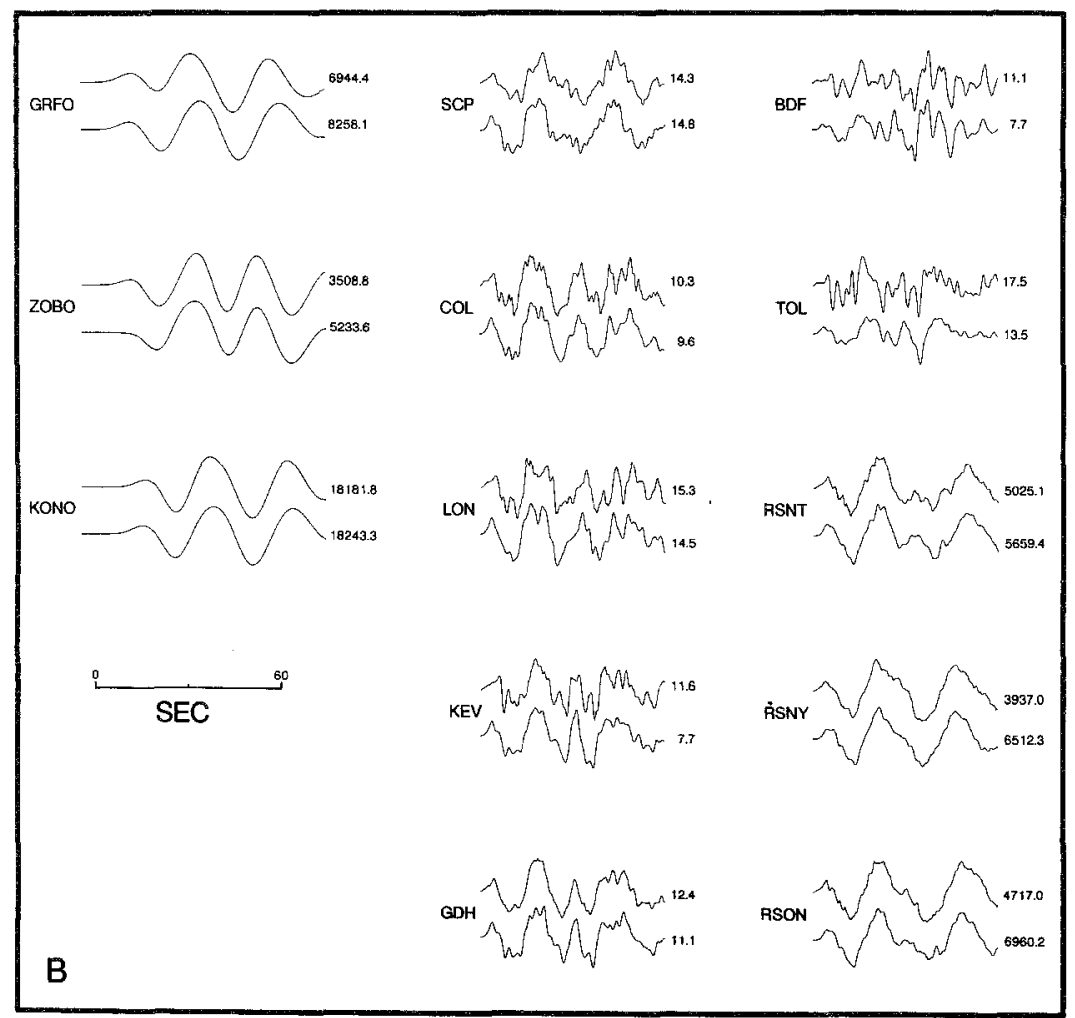

Fig. 9. Comparison of observed (upper trace) and synthetic (lower trace) records for the dislocation model obtained in the time-window analysis. (A) Strong-motion velocity records with peak amplitudes given in $\mathrm{cm} / \mathrm{sec}$. (B) GDSN teleseismic waveforms with peak amplitudes given in hundreds of digital counts. Amplitudes of the synthetics in (A) and (B) correspond to a seismic moment of $1.5 \times 10^{28}$ dyne$\mathrm{cm}$. 
We present the cumulative strike-slip and dip-slip displacement on the fault plane within each of the three time intervals, $T_{1}, T_{2}$, and $T_{3}$. Not surprisingly, the distribution of slip is similar to the single-window result shown in Figure 5. However, we consider the positions of the sources on the fault plane to be better resolved in the time-window inversion due to our relaxation of the fixed rupture time of each subfault. The time-window result, which is obtained by minimizing the total moment, does not require the large 5.5-meter peak slip observed for the deeper downdip source in the single-window inversion. Also, most of the slip within this downdip source appears to occur later and may indicate that a slightly lower rupture velocity would be more appropriate for this source region. However, when we attempted to invert the data using rupture velocities of 2.3 and $2.0 \mathrm{~km} / \mathrm{sec}$, we obtained a poorer overall fit to the observed waveforms without significantly changing the general positions of the regions of maximum slip.

Figure 9 is a comparison between the observed records and the synthetic waveforms of our final dislocation model obtained in the time-window analysis. Because subfaults now slip more than once to accommodate contributions to the observed data, the synthetics approximate the observations more closely than in any singlewindow inversion. The synthetic waveforms correspond to a seismic moment of 1.5 $\times 10^{28}$ dyne-cm estimated from the slip model of Figure 8 . This value is slightly greater than the moment computed by other workers (Ekström and Dziewonski, 1986; Priestley and Masters, 1986; Riedesel et al., 1986) from an analysis of teleseismic data ( 1.0 to $\left.1.1 \times 10^{28} \mathrm{dyne}-\mathrm{cm}\right)$ and is almost equivalent to the seismic moment that we inferred from the teleseismic $P$ waveforms alone $\left(1.4 \times 10^{28}\right.$ dyne$\mathrm{cm}$, Mendoza and Hartzell, 1988). The difference in moment may partly be due to our use of a more complicated near-source crustal structure, although the values are similar considering the uncertainties involved in the computation of seismic moment.

\section{CONCLUSIONS AND Discussion}

We have inverted the strong-motion data recorded at four stations of the Guerrero accelerograph array and the available GDSN teleseismic $P$ waveforms to determine the distribution of fault slip during the 19 September 1985 Michoacan, Mexico, earthquake. Our inversion results support the hypothesis that coseismic slip involved the failure of several large asperity zones distributed along a $150-\mathrm{km}$ segment of the plate boundary between the Cocos and North American plates. A similar distribution of asperities is implied by the results of independent analyses of teleseismic $P$-waveform data alone (Houston, 1987; Mendoza and Hartzell, 1988). Our preferred dislocation model yields a pattern of slip that contains three major sources of predominantly dip-slip motion. One source, near the hypocenter, covers an $80 \mathrm{~km}$ by $55 \mathrm{~km}$ area and has a peak slip of 6.5 meters. Two additional sources are present on the southeast portion of the fault plane about $70 \mathrm{~km}$ away from the hypocenter. One of these covers a depth range of 10 to $24 \mathrm{~km}$ and an area of $45 \mathrm{~km}$ by $60 \mathrm{~km}$. The other source is further down dip at depths between 27 and $39 \mathrm{~km}$ and covers a $30 \mathrm{~km}$ by $60 \mathrm{~km}$ area. Peak slips for the shallow and deep sources are 5 meters and 3.1 meters, respectively.

A multiple-source rupture history had been initially proposed for the Michoacan earthquake from a consideration of point and line sources (Eissler et al., 1986; Ekström and Dziewonski, 1986; Houston and Kanamori, 1986; Priestley and Masters, 1986; Riedesel et al., 1986). The results of the present study, which takes into account the lateral and down-dip extent of the fault, further suggest that the large source near the hypocenter and the two separate sources on the southeast portion 
of the fault were responsible for the observed data. Contributions from the two southeast sources resulted in the second pulse observed in the long-period and many of the intermediate-period teleseismic $P$ waveforms. This observation implies that a higher degree of complexity can exist than is indicated by a cursory investigation of the recorded waveforms. That is, several asperity regions can contribute to a single pulse in the record, and the spatial distribution of the source regions can only be obtained from a three-dimensional analysis of the moment release along the fault.

Considering the decreased sensitivity of the near-source records to displacements in the deeper portion of the fault, the small downdip source is mostly controlled by the teleseismic data. Teleseismic responses for updip and downdip sections of the fault are sufficiently different (Fig. 6) to allow the inversion procedure to distingush between shallow and deep contributions to teleseismic waveforms. This observation, together with the poor fits obtained when we inverted the data using lower values of rupture velocity, suggest that the downdip source is real and not an artifact resulting from an inappropriately high rupture velocity. Also, the source is probably not the result of our parameterization, as is evidenced by the remarkable similarity between our slip distribution and the positions of the areas of maximum moment release computed by Houston (1987) using the Kikuchi and Fukao (1985) method. Their method imposes no constraints on rupture time.

There is some indication from the results of Ekström and Dziewonski (1986) and Houston and Kanamori (1986) that the earthquake lasted longer than 60 sec. However, only one of the GDSN intermediate-period records that we inverted (station GDH) contains a significant pulse beyond $60 \mathrm{sec}$ of the $P$-wave arrival. For the remainder of the intermediate-period records, such a pulse is either nonexistent or has an amplitude smaller than 30 per cent of the $P$-wave maximum. In addition, evidence for a source duration longer than $50 \mathrm{sec}$ is not distinctly observed in the strong-motion data. Thus, any moment release occurring after 50 to 60 sec is probably a small fraction of the total seismic moment.

The strong similarity between the teleseismic models (Mendoza and Hartzell, 1988; Houston, 1987) and the pattern of fault slip that we determined using only the near-source records supports the use of teleseismic $P$ waveforms for inferring the slip distribution in the absence of strong-motion recordings. When strongmotion data are also available, however, a more detailed model can be obtained given adequate station coverage. In our analysis of the 1985 Michoacan earthquake, for example, the near-source records impose strong constraints on the variation of slip across the shallow portion of the fault. The teleseismic data, besides helping identify the timing of the strong-motion records relative to our assumed velocity model, also provide important constraints on the distribution of slip in the deeper sections of the fault and help resolve the positions of the individual sources.

Except for the large 7.5 $M_{s}$ earthquake that occurred on September 21, aftershocks following the 19 September 1985 Michoacan earthquake did not exceed magnitude 5 (Anderson et al., 1986). In Figure 10, we compare the best-located aftershocks of Stolte et al. (1986) to the areas of maximum slip that we obtain in this study. The aftershocks cover the time period of September 22 to October 5 and have hypocentral errors that do not exceed $9 \mathrm{~km}$ and $6 \mathrm{~km}$ in the horizontal and vertical directions, respectively. In general, the seismic activity occurs mostly outside of the regions of maximum slip. This is less apparent for the shallow source on the southeast portion of the plate-boundary segment. However, aftershock activity in this region may be further complicated by the location of the 21 September 1985 earthquake. This second earthquake had a mechanism that is almost identical to that of the 19 


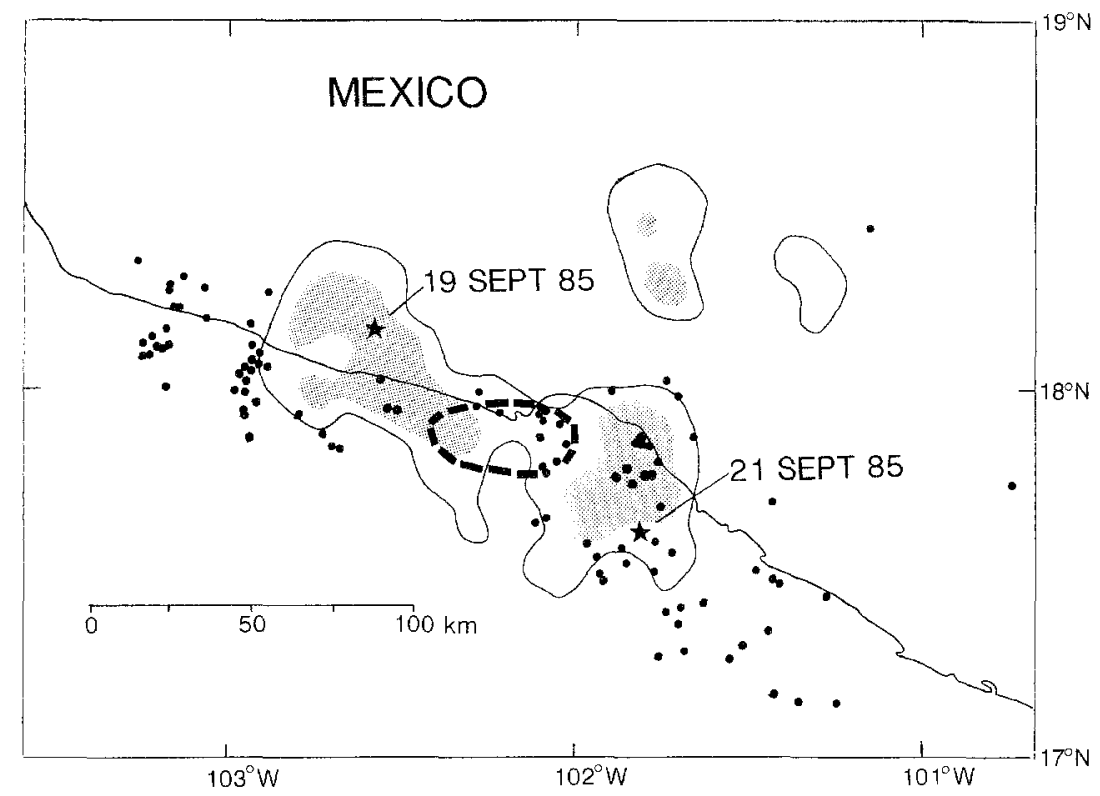

FIG. 10. Comparison of the preferred dip-slip dislocation model from Figure 8 with the distribution of aftershocks following the 1985 Michoacan earthquake. Areas of slip greater than 1.5 meters are shown projected to the surface of the Earth. Areas of maximum slip (greater than 2.5 meters) are stippled. The aftershock region from Figure 1 of the 1981 Playa Azul earthquake is also shown (dashed). The star symbols are the epicenters of the 19 September and 21 September 1985 earthquakes.

September 1985 event (Eissler et al., 1986; Riedesel et al., 1986) and may have ruptured an adjacent portion of the plate boundary to the southeast.

The two larger sources on the shallow portion of the plate interface are separated by an area comparable to the zone of aftershock activity observed following the 1981 Playa Azul earthquake (Fig. 10). Although the pattern of main shock faulting is not known for the Playa Azul earthquake, its aftershock distribution suggests that this region had reduced slip during the 19 September 1985 Michoacan earthquake because most of its accumulated strain was released in 1981. A more detailed investigation of the Playa Azul and 21 September 1985 earthquakes would help identify the mechanics of interplate rupture along this portion of the Middle America subduction zone and would provide some insight into the forecasting of future events in the region.

\section{ACKNOWLEDGMENTS}

Strong-motion data from the Guerrero accelerograph array were made available by the Institute of Geophysics and Planetary Physics of the University of California, San Diego, and the Instituto de Ingenieria at the Universidad Nacional Autónoma de México, Mexico City. We thank John Anderson for supplying these data. We also thank Alfonso Reyes for providing hypocentral locations for the Michoacan aftershock sequence. Critical reviews of the manuscript by George Choy, Bill Spence, Dave Boore, and Göran Ekström proved very valuable at various stages of preparation.

\section{REFERENCES}

Anderson, J. G., P. Bodin, J. N. Brune, J. Prince, S. K. Singh, R. Quaas, and M. Oñate (1986). Strong ground motion from the Michoacan, Mexico, earthquake, Science 233, 1043-1049.

Eissler, H., L. Astiz, and H. Kanamori (1986). Tectonic setting and source parameters of the September 19, 1985 Michoacan, Mexico earthquake, Geophys. Res. Lett. 13, 569-572.

Ekström, G. and A. M. Dziewonski (1986). A very broad band analysis of the Michoacan, Mexico, earthquake of September 19, 1985, Geophys. Res. Lett. 13, 605-608.

Hartzell, S. H. and T. H. Heaton (1983). Inversion of strong ground motion and teleseismic waveform 
data for the fault rupture history of the 1979 Imperial Valley, California, earthquake, Bull. Seism. Soc. Am. 73, 1553-1583.

Hartzell, S. H. and T. H. Heaton (1986). Rupture history of the 1984 Morgan Hill, California, earthquake from the inversion of strong motion records, Bull. Seism. Soc. Am. 76, 649-674.

Houston, H. (1987). Source characteristics of large earthquakes at short periods, Ph.D. Thesis, California Institute of Technology, Pasadena, California.

Houston, H. and H. Kanamori (1986). Source characteristics of the 1985 Michoacan, Mexico earthquake at periods of 1 to 30 seconds, Geophys. Res. Lett. 13, 597-600.

Kikuchi, M. and Y. Fukao (1985). Iterative deconvolution of complex body waves from great earthquakes-The Tokachi-Oki earthquake of 1968, Phys. Earth Planet. Int. 37, 235-248.

Lawson, C. L. and R. J. Hanson (1974). Solving Least Squares Problems, Prentice-Hall, Englewood Cliffs, New Jersey.

Mendoza, C. and S. H. Hartzell (1988). Inversion for slip distribution using teleseismic $P$ waveforms: North Palm Springs, Borah Peak, and Michoacan earthquakes, Bull. Seism. Soc. Am. 78, 10921111.

Olson, A. H., J. A. Orcutt, and G. A. Frazier (1984). The discrete wavenumber/finite element method for synthetic seismograms, Geophys. J. R. Astr. Soc. 77, 421-460.

Priestley, K. F. and T. G. Masters (1986). Source mechanism of the September 19, 1985, Michoacan earthquake and its implications, Geophys. Res. Lett. 13, 601-604.

Riedesel, M. A., T. H. Jordan, A. F. Sheehan, and P. G. Silver (1986). Moment tensor spectra of the 19 Sept 85 and 21 Sept 85 Michoacan, Mexico, earthquakes, Geophys. Res. Lett. 13, 609-612.

Stolte, C., K. C. McNally, J. González-Ruiz, G. W. Simila, A. Reyes, C. Rebollar, L. Munguía, and L. Mendoza (1986). Fine structure of a post-failure Wadati-Benioff zone, Geophys. Res. Lett. 13, 577580 .

\section{U.S. Geological SURVey}

NAtional EarthQuake Information Center

BoX 25046, MS 967

Denver, Colorado 80225

(C.M.)

Manuscript received 22 August 1988
U.S. Geological Survey

CALIFORNIA INSTITUTE OF TEChNOLOGY

Seismological Laboratory, 252-21

Pasadena, California 91125

(S.H.H.) 